\title{
Las tecnologias de información y comunicación como respuesta a la libertad del diseño
}

Information technology and communication as response to design in freedom

> Mónica Fernández Colombo

GIDCAD (Grupo de Investigación y

Docencia en Computación Aplicada al Diseño

FAU-UB (Facultad de Arquitectura y Urbanismo -

Universidad de Belgrano) Buenos Aires - Argentina

monica.fernandez@ub.edu.ar

> Adriana Granero

FAU-UB (Facultad de Arquitectura y Urbanismo Universidad de Belgrano) Buenos Aires - Argentina adriana.granero@comunidad.ub.edu.ar
> Liliana Telma Bonvecchi

labPRa (Laboratorio de Proyecto Arquitectónico)

FAU-UB (Facultad de Arquitectura y

Urbanismo - Universidad de Belgrano)

Buenos Aires - Argentina

liliana.bonvecchi@ub.edu.ar

> Mabel Brignone

FAU-UB (Facultad de Arquitectura y

Urbanismo - Universidad de Belgrano)

Buenos Aires - Argentina

mabel.brignone@comunidad.ub.edu.ar

\section{Abstract}

As educators, we have been witness and party of ICT's application in teaching architecture. From computer assisted design, representation models, dynamic and interactive visualization, until the arrival of digital fabrication, the incorporation of augmented reality and the interaction on mobile devices. Reflections on digital technology have generated discussions on architectural theory in order to find the source of architectural language inspirations. We find ourselves today in a context of important intellectual renewal aimed at the design in freedom.

Keywords: Education - Architectural Lenguage - Digital Fabrication

\section{Introducción}

"La tecnología es la respuesta, pero ¿cuál era la pregunta?”. Con esta frase de Cedric Price (arquitecto británico 1934/2003) damos introducción a la temática: "las tecnologías de información y comunicación como respuesta a la libertad del diseño”. Para iniciar un trabajo de investigación, es habitual el planteo de una pregunta, cuya respuesta no se constituye en una idea, sino en una solución. La pregunta plantea el objetivo y sus límites, así como el producto final. La respuesta plantea una hipótesis, una teoría y la naturaleza del producto que va a dar respuesta a la formulación. La etapa de desarrollo de la investigación incluye una estrategia que valida resultados y se encuadra en la teoría de la decisión, es decir concierne a la identificación de la mejor decisión que pueda ser tomada, asumiendo un entorno de completa información. La toma de decisiones es el proceso mediante el cual se realiza una elección para resolver diferentes situaciones en diversos contextos. La aplicación práctica de esta aproximación a la toma de decisiones, proporciona una búsqueda de herramientas y metodologías que colaboran con la respuesta que otorgue la mayor libertad del diseño.

En tanto educadores, hemos sido testigos y parte en la aplicación de las TICs a la enseñanza de la arquitectura, desde el diseño asistido por computadora, con sus modelos de representación y visualización dinámica e interactiva, hasta la llegada de la fabricación digital, la incorporación de la realidad aumentada y la interacción con dispositivos móviles en diversas propuestas. Las reflexiones sobre la tecnología digital aplicada al proyecto arquitectónico, han generado un debate orientado a la teoría de la arquitectura en la búsqueda del origen de inspiraciones proyectuales. Hoy nos encontramos inmersos en un contexto de importante renovación intelectual tendiente a la libertad del diseño. Referentes como Zaha Hadid, Bernard Tschumi, Norman Foster, o Farshid Moussavi han instalado un pensamiento multidisciplinar que reúne las matemáticas, la biología, la filosofía, la ética, en el pensamiento común del proyecto arquitectónico.

En el ámbito académico hemos atendido a las capacidades del diseñador y sus posibilidades de proponer en libertad, tomando como base lo que él mismo puede crear y no lo que las herramientas son capaces de hacer. Nuestra tarea se centra hoy en la fabricación digital y en la formación de recursos humanos en este ámbito específico como respuesta a los propósitos de operar con el lenguaje arquitectónico. Sin embargo, dado el interés en las tecnologías capaces de materializar alternativas tridimensionales, debemos estar alertas respecto de las consecuencias inesperadas que toda aplicación de una nueva tecnología conlleva. Por ello ponemos el énfasis más en la pregunta que en la respuesta.

\section{Metodología y Materiales}

Detectamos dos tendencias importantes: la llegada de los medios digitales al entorno urbano y el resurgimiento de lo decorativo en el diseño y en la arquitectura. Así como la tecnología digital ha ingresado en el entorno construido, los medios de comunicación 
han influido en la estética, la organización y el uso del espacio urbano y arquitectónico.

Lo virtual, expresión propia de la década de 1990, describía entornos generados por computadora que provocaban el replanteamiento del espacio. En el discurso arquitectónico contemporáneo, el debate se centra en el problema y estructura de los acontecimientos, porque el lugar en términos tradicionales ha dejado de existir. Bernard Tschumi fue uno de los primeros arquitectos en cuestionar el carácter estático y permanente del entorno construido: “...la apariencia de la permanencia es desafiada por la representación inmaterial de los sistemas abstractos"b.

El diseño asistido por computadora ha generado un fuerte impacto en la práctica proyectual, ya sea como herramienta sencilla y de reflexión teórica básica, o como propuesta de vanguardia aplicada a prácticas experimentales. Sin embargo, tanto la arquitectura de tablero, como la de pantalla y la de objetos físicos, despliegan un espacio multidisciplinar para la creación, y se constituyen en oportunidad única para presentar alternativas proyectuales que colaboren con las decisiones del lenguaje arquitectónico.

Lo digital parece capaz de romper las barreras entre las disciplinas sin ocultar la renovación intelectual y arquitectónica por la que atraviesa la práctica proyectual. Este campo otorga una nueva dirección a la investigación arquitectónica, permitiendo experimentar con las posibilidades ofrecidas por las nuevas herramientas. El diálogo entre arquitectura, ingeniería y medios digitales está en el núcleo de estas experiencias.y pone en juego el equilibrio entre diseño y fabricación. La aplicación de los equipos y software de modelado tridimensional como herramientas, ha influido en los procesos de diseño y fabricación de la arquitectura y, en consecuencia, en la forma y el aspecto de los edificios y sus superficies.

Para Frank Gehry: "Demasiado a menudo, el término arquitectura digital se encuentra asociado con la expresión en el futuro"c, dado que en cualquiera de las modalidades digitales se opera sobre la promesa y no sobre la realidad. Por otro lado, el problema del diseño digital consiste en que parte de lo que produce, conserva la impronta de la herramienta que lo construyó. El desarrollo de las aplicaciones realizadas en el campo de la investigación académica que presentamos, se fundamenta en opciones educativas basadas en el uso de la tecnología. Estas experiencias realizadas en laboratorio, promueven la capacidad creativa, crítica y la facultad de construir conocimiento atendiendo a la libertad del diseño. Estas acciones conllevan la adaptación de los programas de estudio al uso de la tecnología digital, así como la implementación de modelos instrumentales de lenguaje arquitectónico. Las experiencias aplican a la modelización digital, a la construcción de modelos físicos y alternativas de envolventes arquitectónicas en modelos digitales de presentación virtual y física.

Desde el comienzo del siglo XXI la tecnología de medios digitales ha sido adoptada por la arquitectura de manera creciente. Los espacios se definen o distorsionan a través de la aplicación de la tecnología de medios digitales. Los dispositivos programables e interactivos aplicados al lenguaje de la arquitectura crean condiciones que permiten una variedad y flexibilidad de usos, así como nuevas formas de conexión individual entre usuario y obra.
En este nuevo contexto los límites físicos se vuelven borrosos. La arquitectura no es más un ente estático y silencioso. Las superficies arquitectónicas están asumiendo las características de los textiles, son cada vez flexibles, ornamentadas y efímeras. La fachada de representación convencional de los edificios se disuelve en superficies de acontecimientos. Las imágenes visuales, constantemente generadas a partir de entornos digitales, invaden el espacio físico. El espacio arquitectónico se transforma en un híbrido, donde lo real y lo virtual se solapan.

La investigación llevada a cabo tiene como finalidad plantear estrategias de integración cognitivas que permitan, a través de modelos constructivos y de simulación, promover la creatividad, la crítica y la experimentación, con el propósito de formar recursos humanos capaces de optimizar sus propuestas proyectuales. Las aplicaciones se llevan a cabo con equipos instalados en laboratorio: pantógrafo laser, router CNC, Kinect, operación de software específico de modelización Rhino. Estos instrumentos y sus aplicaciones, posibilitan el diseño paramétrico, el uso de algoritmos y posteriormente, la vinculación con periféricos de salida que acompañan el proceso de fabricación digital. También se realizan aplicaciones tales como simulaciones, realidades mezcladas, proyecciones y reconocimiento del entorno por medio de proyectores y captadores. Se presentan trabajos de aplicación sobre casos concretos de lenguaje arquitectónico, en función de proyectos realizados en el curso de la asignatura Trabajo Final de Carrera, correspondiendo a la práctica proyectual del último año de Arquitectura.

\section{Resultados}

Las aplicaciones que se presentan resultan de analizar los puntos de convergencia entre disponibilidad tecnológica y poética ornamental en la configuración de los lenguajes arquitectónicos. La intención es estudiar las posibilidades expresivas y la estructuración de un orden espacial en las envolventes, surgido de la dimensión genética de las formas. No se trata solamente de la selección de motivos gráficos para ser aplicados a los volúmenes edificados, sino de constituir esos motivos en operadores espaciales, o de movimiento, por vía de las tecnologías digitales aplicadas al diseño.

Los ejes principales desde el punto de vista técnico en el campo de la concreción final de la arquitectura, son los siguientes:

- La arquitectura como soporte de imágenes reproducidas mediante mapeados digitales; utilizar el ornamento intencionadamente como un medio para disolver y desestabilizar la fachada convencional; aplicación de secuencias de imágenes que cubren por completo la fachada, a la manera de un tatuaje. El muro como imagen desmaterializa el edificio real, convirtiendo la fachada en una entidad epidérmica que funciona como soporte. (Figura 1) (Figura 2)

- La envolvente arquitectónica como pantalla mediática; la tecnología, en combinación con un material transparente, ańade ambigüedad a la arquitectura, expresando misterio e incertidumbre; desmaterializar la arquitectura, haciendo de ella una cuestión de luz y de efectos de superficie; integrar en la arquitectura y el espacio urbano imágenes en movimiento; producir efectos inmersivos a partir de 
narrativas contextualizadas con una diversidad de contenidos. (Figura 3) (Figura 4)

- La generación de fachadas a partir de procedimientos algorítmicos; innovaciones en el diseño de los límites de los objetos edificados como base de una poética productiva "plegable" y flexible, que enfatiza las conexiones entre elementos y permite crear espacios que conduzcan a nuevas versiones de envolventes arquitectónicas; facilitar mecanismos abiertos y creativos en el entorno de la arquitectura paramétrica, tanto desde lo proyectual como desde los sistemas que hacen a la materialidad constructiva. (Figura 5) (Figura 6)

\section{Debate}

En función de lo expuesto, se instala un debate referido a los diseños paramétricos que den respuesta a la pregunta por la incorporación de las herramientas digitales según nuestra propia selección, ampliando el campo decisional para un diseño en libertad.

El discurso arquitectónico, sobre la aplicación y la implementación práctica de la tecnología digital, está todavía en sus comienzos, considerando el campo ampliado de la historia de la arquitectura reciente. Incluso los proyectos construidos todavía conservan las características de los prototipos. Algunos ejemplos están en la fase de ser desarrollados comercialmente. Todavía se trata de un vasto campo inexplorado. La fusión de la arquitectura y la tecnología digital ha definido un nuevo punto de referencia en la práctica arquitectónica.

Algunas prácticas actuales, como la interactividad en la arquitectura, son consecuencia del incremento de la comunicación a partir de dispositivos digitales. Los nuevos métodos y herramientas están en constante evolución. La búsqueda de una estética coherente con este contexto constituye el desafío presente. Artistas y arquitectos han comenzado a explorar la interactividad dentro de la arquitectura de muchas maneras diferentes.

Esto se demuestra no sólo a través de proyectos experimentales, sino también a través del debate y el intercambio entre académicos y profesionales acerca de la arquitectura mediática, las pantallas urbanas y los diseños paramétricos. Conferencias y publicaciones se dedican a este tema, y las escuelas de arquitectura han comenzado a incluirlas en su programa de enseñanza.

\section{Citas}

a. A'A' 397 L'Architecture d'aujourd'hui - Architecture Numérique septiembre 2013.

b. Tschumi, Bernard, Event Cities, MIT Press, Cambridge, 1994. Lee (2007) shows that...

c. A'A' 397 L'Architecture d'aujourd'hui - Architecture Numérique septiembre 2013.

\section{Referencias}

A'A' 397 L'Architecture d'aujourd'hui - Architecture Numérique septiembre 2013.
Instituciones Académicas.- Realidades virtuales aumentadas para el desarrollo social, Experiencias entre Europa y Latinoamérica. Proyecto ALFA GAVIOTA, Universidad de Belgrano 2014.

Bullivant, Lucy. 4dspace: Interactive Architecture (Architectural Design) Ed. John Wiley \& Sons London 2005

Koolhaas, Rem, Phylogenesis: foa's ark, Actar, Barcelona, 2003.

Mirzoeff, Nicholas, The Visual Culture Reader, Routledge, London, 2012.

Moussavi, Farshid, The Function of Ornament, Actar, Barcelona, 2006

Stott, R. "The Depreciating Value of Form in the Age of Digital Fabrication" 13 Apr 2014. ArchDaily. Accessed 15 Apr 2014. <http://www.archdaily.com/?p=495089>

Tschumi, Bernard, Event Cities, MIT Press, Cambridge, 1994.

\section{Figuras}

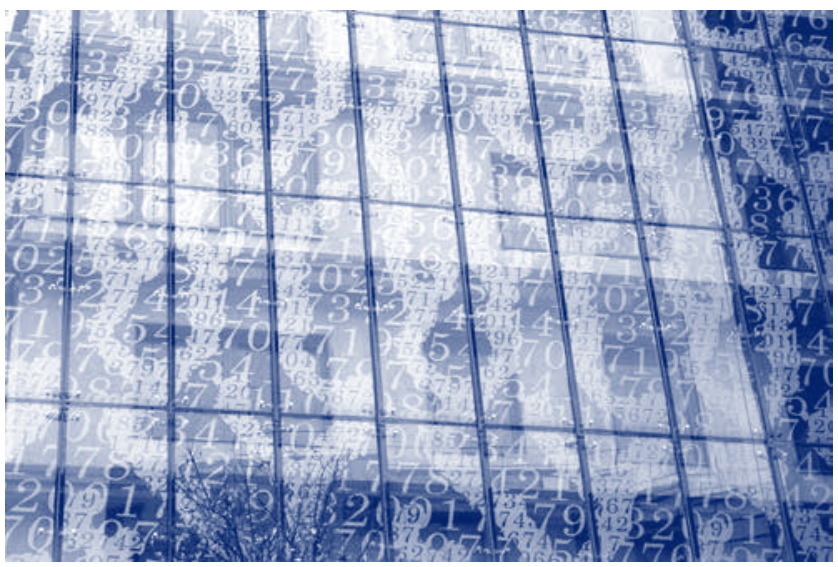

Figura 1: Université Paris VII, UFR de physique, e Chaix \& Morel et Associés.

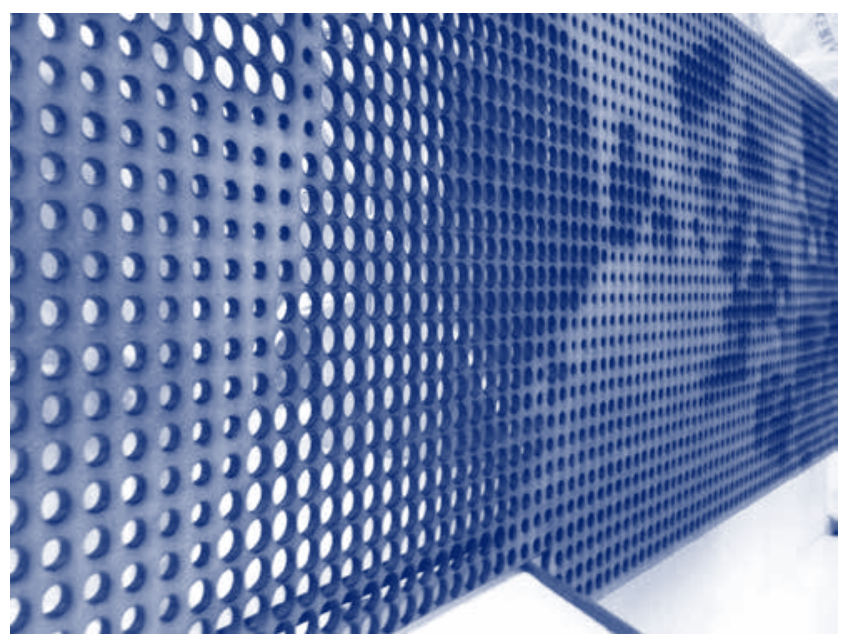

Figura 2: Mapeado digital en laboratorio Alfa Gaviota. 


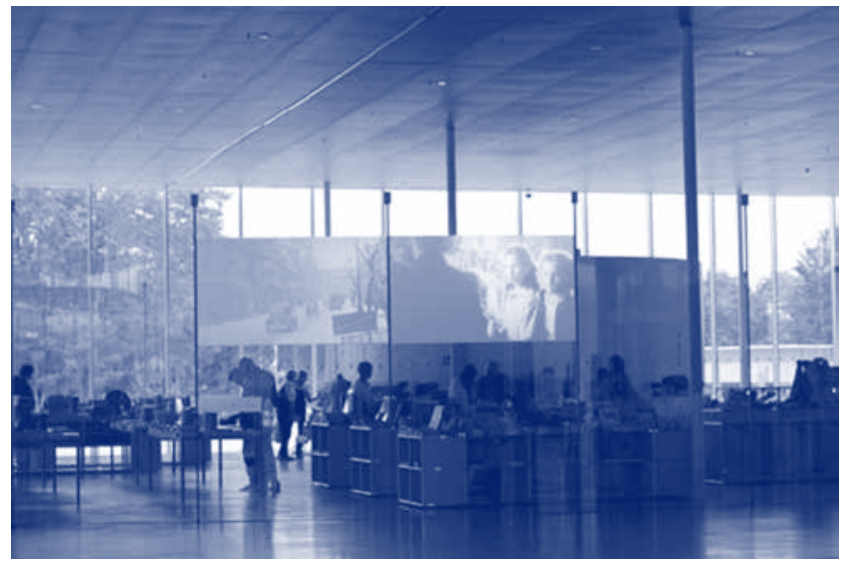

Figura 3:Musée du Louvre - Lens, SANAA.

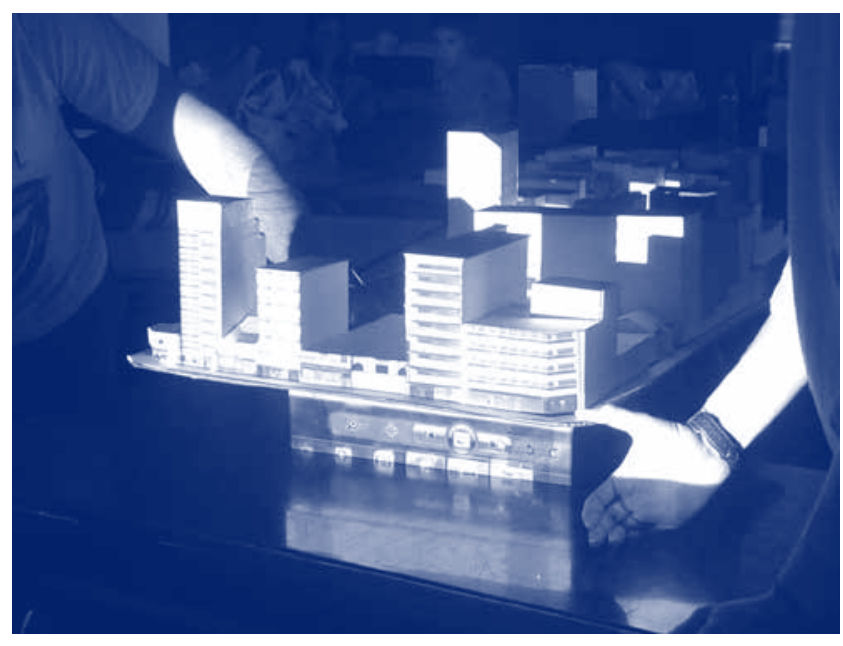

Figura 4: Pantalla mediática, experiencia de taller.

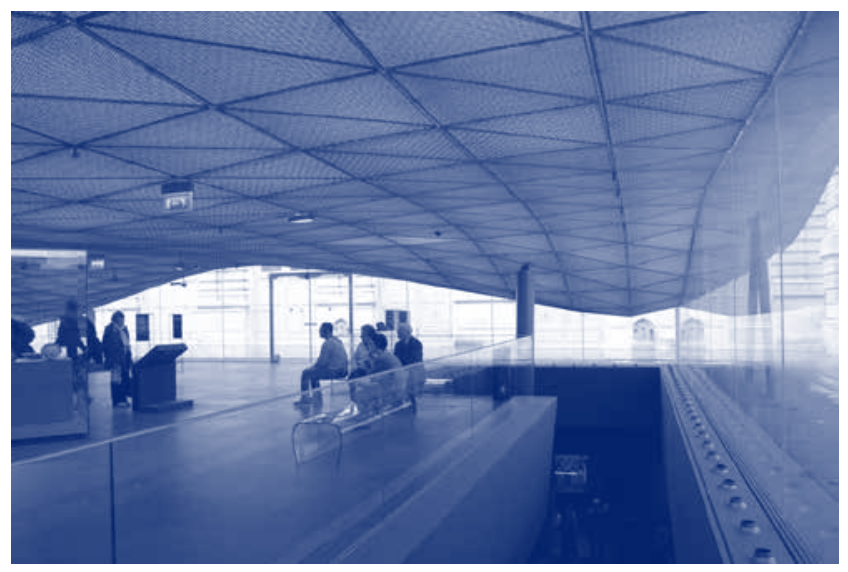

Figura 5: Arts de l'Islam, Cour Visconti, Musée du Louvre, Paris, Rudy Ricciotti y Mario Bellini.

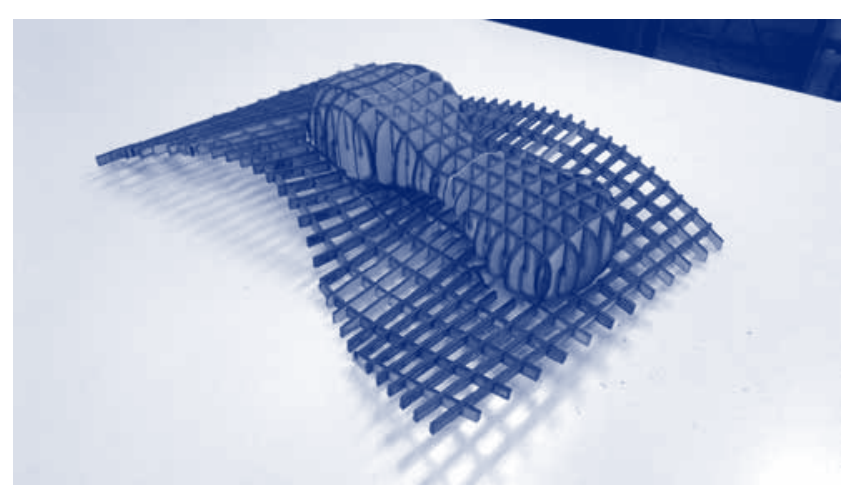

Figura 6: Procedimientos algorítmicos, experiencia en laboratorio. 